\title{
ABSTRACTS
}

\section{IMPLICIT REINFORCEMENT IN THE CLASSROOM}

\author{
by \\ Takeshi Sugimura \\ Nara Gakugei University
}

The purpose of the present experiment was to test whether or not the implicit reinforcement effect, recently found by Sechrest(1963) under paired groups, also occurred in competitive classroom situations.

The Ss were 4 th, 5 th, and 6 th grade children, consisting of 3 classes in each grade. Two of 3 classes were assigned to the experimental groups and the remainig one to the control. All Ss were given additional tasks, such as $4+9+8+7$, under competitive instructions, for 4 minutes a day in two successive days. Ss in each experimental group were divided into 2 subgroups, equating the lst day's performance and the number of both sexes. Just before the beginning of the 2nd day's task, Ss in one subgroup of the lst experimental class were praised (positively reinforced) for their lst day's performances and those of the 2nd experimental class were reproved (negatively reinforced), while the rest of Ss in two experimental classes were not given any comments on their performances. It seems that $\mathrm{Ss}$ who observed the praised or reproved classmates might be reinforced implicitly rather than explicitly. After the task had been finished, introspective reports were collected where responses were made by chosing one of two predetermined state- ments on the impressions about the verbal reinforcements.

The main results were, as is shown in Tables 1 and 2, that (a) Ss who observed the explicitly reproved classmates (IP group in Table 1) yielded similar results to the explicitly praised Ss (EP group), (b) Ss in IP group performed significantly better than those who observed the explicitly praised classmates (IN group) did, and (c) a significant grade $\times$ type $\times$ condition interacion was found, suggesting that implicit reinforcement effect mainly occurred in 6th grade children, while the ex plicit praise was more effective in 4 th and 5 th graders. From the introspective reports as inTable 3 , it was evident that (d) most Ss in IP group wished not to be reproved on the following task, and most Ss in IN group wished to be praised like their classmates.

It was concluded that the implicit reinforcement effect was also found in the classroom situation. Implications of the present results for classroom settings and relationships between the present study and Hurlockian experiments on verbal reinforcements were discussed. 